\title{
CONSIDERATIONS ON THE APPLICATION OF EUROCODES 2 AND 4 FOR CONCRETE BRIDGES
}

\author{
PHILIPPE VAN BOGAERT \\ Dept of Civil Engineering, Ghent University, Gent, Belgium
}

\begin{abstract}
The application of certain parts of Eurocodes may result in surprising conclusions. Three independent examples of code requirements are presented. A first striking example is the fatigue compression resistance of RC or PC bridge girders and the prediction of the resulting lifetime, which may be excessively low. The second issue concerns the limiting value of slenderness of concrete arches, which shows no logical relation to the load bearing capacity. An alternative for the definition of slenderness is proposed. The third item is the necessity to consider an uplift force in the design of connectors, thus excluding virtually the use of block connections. In all three cases, alternatives are being proposed, needing further research or allowing a different approach to these issues. In addition, clarification of some code recommendations may overcome misunderstanding or erroneous application.
\end{abstract}

Keywords: Structural verification, Concrete fatigue, Use of codes, Arch stability, Block connectors.

\section{INTRODUCTION}

Eurocodes have become a valuable standard in bridge design and are applied on a wide scale. In general, their application has been strongly implemented, even outside Europe. Any discussion or verification of structural designs is based on these documents. However, these codes are referred to even if some applications are not covered by the text, or a particular case is tried to be solved by methods that were not intended for the typical details under consideration. In addition, some parts of the text give the impression that they are absolutely of a general character, whereas they might fail in certain fields.

In this paper three striking examples are shown for which the Eurocodes may seem to render unexpected results. The reasons for this may be the recommendations made based on a small number of test results, or a restrictive interpretation. Other possibilities may be inappropriate generalization or the intention to eliminate certain methods or details. Since few background documents have been released, the exact information is limited.

However, for each of the three cases, solutions are being presented, which need to be substantiated further. Hence, this contribution invites to reflect further on these application issues, in order to eliminate possible ambiguity in standards.

\section{FATIGUE RESISTANCE OF CONCRETE PRESTRESSED PRECAST BRIDGE BEAMS}

Eurocode 2 and 4 (EN 1992 - EN 1994) provide requirements for fatigue verification, both of reinforcements and prestressing steel, as for concrete itself. The fatigue resistance of 
reinforcements is identical as for construction steel, albeit the slope of the S-N-curves is fundamentally different. In addition, concrete fatigue resistance must also be verified by a set of formulas. The latter are completely consistent with the fatigue mechanism in concrete, which is mainly due to compressive deterioration rather than to stress concentrations. Progressive fatigue damage does not depend on stress variations between maximum and minimum values, but rather on the ratio $\mathrm{R}$ of minimum to maximum value and on both the ratios of maximum stress to the design fatigue strength $f_{c d, f a t}$ and of minimum stress to $f_{c d \text { fat }}$. Thus, the Paris' law, used in steel structures is replaced by a procedure close to the Goodman-Smith approach. In addition, EN 1992-2 (2008) for bridges allows determining the ultimate number $\mathrm{N}_{\mathrm{i}}$ of constant amplitude cycles corresponding to failure, by Eq. (1):

$$
N_{i}=10^{14\left(1-\frac{E_{c d \max , i}}{\sqrt{1-R_{i}}}\right)}
$$

In this formula $\mathrm{E}_{\mathrm{cdmax}, \mathrm{I}}$ is the maximum compression stress level and $\mathrm{R}_{\mathrm{i}}$ is de ratio of lower to upper stress during one cycle. Annex $\mathrm{NN}$ of the same standard allows fatigue verification by the principle of Miner's rule and damage equivalent stress. Hence, knowing the importance of the road, type of traffic and number of vehicles per year, the required number of cycles for 100 year life time can be compared to the result of expression (1). This was done for a series of bridges, consisting of $4 \mathrm{RC}$ culverts, $4 \mathrm{PC}$ road bridges and 4 PC railway bridges, all at least 20 years of age and in good condition. Table 1 shows the result for the $\mathrm{PC}$ beams of the 4 railway bridges.

Table 1. Fatigue resistance and life duration for PC beams of 4 railway bridges.

\begin{tabular}{ccccc}
\hline Location & Leuven bend & Leuven viaduct & $\begin{array}{c}\text { Krochtenstr E 19 } \\
\text { motorway }\end{array}$ & KW 32 Diabolo \\
\hline Span & $30.25 \mathrm{~m}$ & $34.6 \mathrm{~m}$ & $13.5 \mathrm{~m}$ & $17.6 \mathrm{~m}$ \\
Max concr stress & 5.14 & 9.75 & 12.13 & 12.13 \\
Min concr stress & 1.838 & 4.91 & 7.28 & 7.28 \\
N (EC2) & $5.97 * 10^{3}$ & $1.24 * 10^{2}$ & $3.05^{*} 10^{3}$ & $4.66^{*} 10^{5}$ \\
Life EC & 0.2 & 0.0 & 0.1 & 18.1 \\
\hline
\end{tabular}

Table 1 shows the stress variations at the lower side of the PC beams. However, the situation is similar at the upper edge of the beams. The loads and number of cycles might be different from the expected quantities, although this does not explain the consistent shortage of strength.

Consequently, none of these cases would comply with the requirements of the code and some of the bridges would not provide adequate resistance to fatigue and would fail within 1 year of service, which obviously does not correspond to reality. It was easily found that this is due to the low value of $f_{c d}$ fat or the effective concrete fatigue resistance. However, today there are many experimental results, as reported by Bun and Espion (2011) concerning $f_{\text {cd fat }}$ contradicting the low values from the code. From these results, the value of $f_{c d}$ fat should at least equal $0.6 f_{c m}$ or be close to $f_{c d}$, the latter being the mean value and the design value of concrete compression resistance. The results are limited to HPC 100/115 and are similar to those found previously for more common types of concrete. 


\section{STABILITY OF CONCRETE ARCH BRIDGES}

A first verification of the importance of the arch stability is given by member 5.8.3 of EN 1992-11 (2005), through the use of the simplified criteria for second order effects. This is based on the verification whether the slenderness of an individual member does not exceed a limit value. This has been applied to 5 concrete arch bridges, built from 1923 to 1932 as reported by Van Bogaert (2014). Figure 1 shows one of these bridges, the Rampe du Lion Bridge, located to the North of Brussels and listed as a monument. The results show that nonlinear material and geometric effects have to be considered, especially for verifying the arch stability.

To verify whether this conclusion is justified, geometric and material nonlinear simulations of these bridges was carried out, in order to determine the failure load. The material nonlinearity was simulated by using the reduced stiffness method from EN 1992-1-1 (2005) and EN 1992-2 (2008). The results of these nonlinear analyzes by the reduced stiffness method, have been summarized in Table 2. Surprisingly the slenderest arches have the largest load factor, or the highest load carrying capacity. In addition, whether the arches are stocky, such as River Emu bridge and Rampe du Lion, or slenderer, the load factor does not seem to vary accordingly. In fact, the bridge with lowest slenderness has the lowest load carrying capacity.

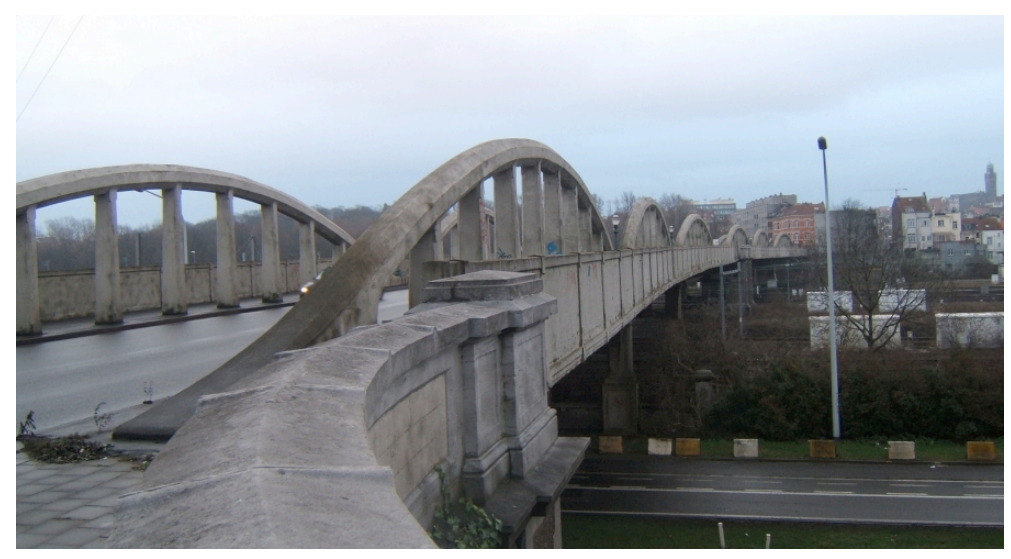

Figure 1. Six span concrete arch bridge Rampe du Lion.

Table 2. Load factor and slenderness of concrete arch bridges.

\begin{tabular}{lccccc}
\hline Bridge & Pontweg & Rampe du Lion & River Emu & Dendermonde & SK Waver \\
\hline Built in & 1926 & 1923 & 1939 & 1932 & 1934 \\
Span & $34.8 \mathrm{~m}$ & $34.4 \mathrm{~m}$ & $32.9 \mathrm{~m}$ & $60 \mathrm{~m}$ & $18 \mathrm{~m}$ \\
Arch rise & $5.41 \mathrm{~m}$ & $5.50 \mathrm{~m}$ & $6.10 \mathrm{~m}$ & $10.75 \mathrm{~m}$ & $6 \mathrm{~m}$ \\
$\lambda$ & 58.17 & 39.83 & 42.35 & 35.52 & 29.71 \\
$\lambda_{\lim }$ & 17.18 & 17.45 & 15.61 & 12.58 & 19.22 \\
load failure factor & 6.1 & 3.61 & 6.8 & 2.37 & 3.85 \\
\hline
\end{tabular}

Hence, it must be clear that the slenderness as defined in the code is probably inadequate for concrete arches. In addition, imperfections of various amplitudes have been considered. Contrary to steel arches, concrete members do not show effects from residual stress. As buckling curves for steel members include the effect of residual stress, thus using increased values for 
imperfections, for concrete the magnitude of imperfections should not contain this increase and may be close to the real values, instead of being equivalent values. Simulations showed that the effect of imperfections is independent of the slenderness and a small imperfection already causes a reduction of $25 \%$ of the load- carrying capacity. If the failure load is defined by the factor $\alpha_{\text {ult }}$ being the factor by which the load must be multiplied to equal the characteristic strength of the structure's cross-section, including material and geometric nonlinearity, buckling and, if relevant, imperfections, a new definition of the slenderness was derived by Van Bogaert and Schotte (2017) as in Eq. (2).

$$
a_{u l t}\left(E_{c m} / E_{\text {red }}\right)=17.351 \lambda^{2}{ }_{\text {red }}-41.326 \lambda_{\text {red }}+26.034
$$

This formula allows determining the factor by which the characteristic loads must be multiplied for structural failure. $E_{\mathrm{cm}}$ and $E_{\text {red }}$ respectively are the mean value of the concrete modulus and the reduced concrete modulus, according to EN 1992-1-1 (2005). This proposed expression was found through nonlinear simulation of a large set of demonstration cases. However, it needs to be substantiated further, both by numerical simulation and experiments.

\section{PULL-OUT OF CONNECTORS OF COMPOSITE BEAM}

In Eurocode EN 1994-1 (2008) part 6.6.1.1 an uplift force between a steel beam and a concrete top slab of 0.1-times the ultimate shear capacity of connectors has to be considered. The origin of the uplift force resides in second order effects and incapacity of the slab to comply with the deformations of the steel beam. Block connectors, consisting of simple bars with rectangular sections, welded to the flanges of steel beams, have effectively been used as connectors in many bridges. Due to the uplift force, either the connectors should be supplemented with welded stirrups, or completely excluded.

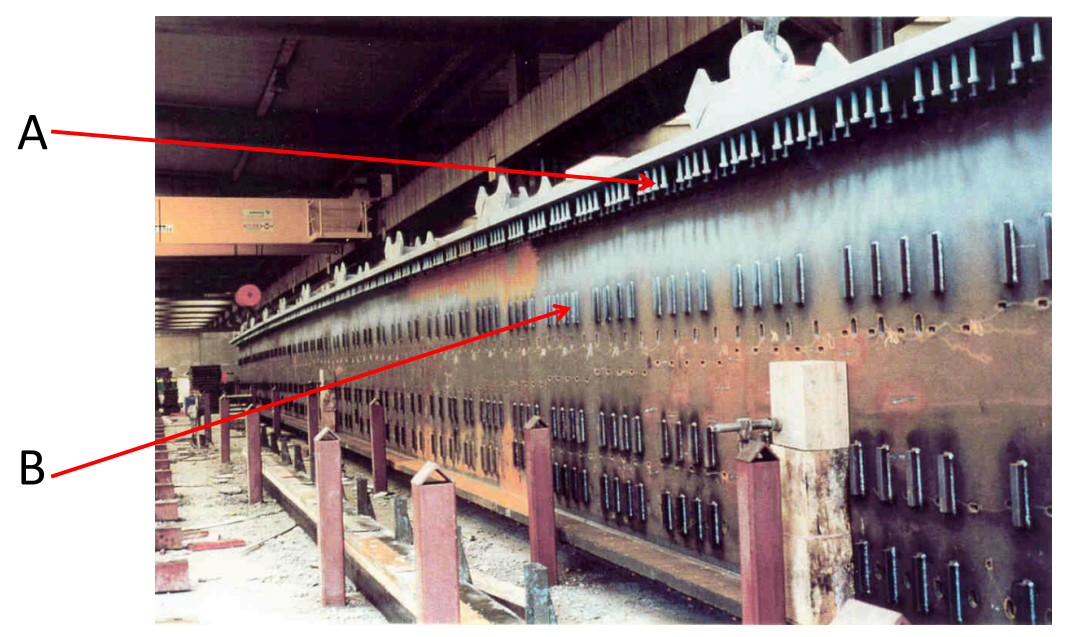

Figure 2. Headed stud (A) and block (B) connectors for shear force transmission.

In the first 1992-version of the code, the use of block connectors was explicitly categorized as non-ductile connector. The contribution of stirrups could be considered only partially, because of their larger deformation. An impressive number of composite bridges have been designed and built, using block connectors exclusively. When verified today for new or exceptional loads, these structures no longer satisfy the requirements. An example of application of block 
connectors is shown in Figure 2, a steel bridge beam to be encased by concrete. The flanges are equipped with headed studs, whereas the webs have steel block connectors, transferring shear force from the steel beam to the encasing concrete.

The concept of block connectors is to develop pure shear resistance through the compression of a truncated pyramid of the encasing concrete. The concrete compression resistance is the main factor to determine the shear capacity. This type of connector does not require supplementing additional rebars and relatively low concrete cover is sufficient.

Various alternatives to headed stud connectors, like perfobond or related, have been developed in recent years. These alternatives mainly consist of a perforated or cut plate, welded to the steel beam or structure. Various shapes of the cutting have been developed, varying from simple holes, a rebar being placed through them, or particular open cut or dowels, also requiring reinforcement bars to interfere with the connection. However, each type requires rather large concrete cover as do headed studs.

Therefore, if the second order effect of uplift can be neglected, which is the case for almost every steel-concrete beam bridge, block connectors may be permitted as mentioned by Classen and Gallwoszus (2015). The importance of the second order effect and uplift of a top concrete slab placed on steel beams can easily be assessed by the nominal stiffness method of EN 1992-1$1(2005)$.

\section{CONCLUSIONS}

Three specific examples have been used to demonstrate that some issues may arise during the application of Eurocodes to bridge designs. This is due to the fact that codes are thought to include every type of problem and may be applied to any particular problem. In the case of fatigue resistance of concrete bridge decks, the fatigue resistance mentioned in the code is extremely low. Recent experimental data indicate that higher concrete fatigue resistance should be allowed. Stability of unbraced arches is governed by their slenderness factor. Eurocode 2 includes a method to assess slenderness and provides limiting values. In the case of concrete arch bridges, the limiting slenderness values are inconsistent with the load-carrying capacity. A proposal to relate slenderness to a load carrying capacity factor is introduced. In a similar manner, according to the relevant code, connectors should be designed for axial force as well as shear. This axial force is due to second order effects, which in general do not exist in steelconcrete bridges. Assessment by the nominal stiffness method may provide an accurate method to determine the importance of the effect and the need to provide axial resistance of connectors.

\section{References}

Bun, P., and Espion, B., Fatigue Behavior of High Performance Concrete in Compression, International RILEM Conference (5-7/9/ 2011: Hong Kong, SAR), Advances in Construction Materials Through Science and Technology, RILEM Publications, Paris, Sept 5-7, 2011.

Classen, M., and Gallwoszus, J., Shear Behavior of Composite Dowels in Transversely Cracked Concrete, Structural Concrete, Elsevier, 16(2), 337-348, June, 2015.

EN 1992-1.1, Eurocode 2: Design of concrete structures - General Rules and Rules for Buildings, CEN, Brussels, 2005.

EN 1992-2, Design of concrete structures - Concrete Bridges -Design and Detailing Rules, CEN, Brussels, 2008.

EN 1994-1.1 Eurocode 4: Design of Composite Steel and Concrete Structures - Part 1-1: General Rules and Rules for Buildings, CEN, Brussels, 2008.

Van Bogaert, Ph., and Schotte, K., Concrete Arch Stability by The Nominal Stiffness Method, 39nd IABSE Symposium - Engineering the Future, Vancouver, Canada, ISBN 9783857481536, September 21-23, 2017. 
Vacanas, Y., Danezis, C., Yazdani, S., and Singh, A. (eds.)

Van Bogaert, Ph., Limiting Slenderness Values of Smaller Concrete Tied Arch Structures, 37nd IABSE Symposium Proceedings, Engineering for Progress, Nature and People, IABSE, Madrid, Spain, ISBN 9783857481345. Sept 3-5, 2014. 